IZA DP No. 9249

Smoking, Drinking, Never Thinking of Tomorrow: Income and Risky Choices amongst Young Adults in the UK

Gianluigi Coppola

Niall O'Higgins

Claudio Pinto

August 2015 


\title{
Smoking, Drinking, Never Thinking of Tomorrow: Income and Risky Choices amongst Young Adults in the UK
}

\author{
Gianluigi Coppola \\ University of Salerno \\ Niall O’Higgins \\ ILO, University of Salerno and IZA \\ Claudio Pinto \\ University of Salerno
Discussion Paper No. 9249
August 2015 \\ IZA \\ P.O. Box 7240 \\ 53072 Bonn \\ Germany \\ Phone: +49-228-3894-0 \\ Fax: +49-228-3894-180 \\ E-mail: iza@iza.org
}

\begin{abstract}
Any opinions expressed here are those of the author(s) and not those of IZA. Research published in this series may include views on policy, but the institute itself takes no institutional policy positions. The IZA research network is committed to the IZA Guiding Principles of Research Integrity.

The Institute for the Study of Labor (IZA) in Bonn is a local and virtual international research center and a place of communication between science, politics and business. IZA is an independent nonprofit organization supported by Deutsche Post Foundation. The center is associated with the University of Bonn and offers a stimulating research environment through its international network, workshops and conferences, data service, project support, research visits and doctoral program. IZA engages in (i) original and internationally competitive research in all fields of labor economics, (ii) development of policy concepts, and (iii) dissemination of research results and concepts to the interested public.
\end{abstract}

IZA Discussion Papers often represent preliminary work and are circulated to encourage discussion. Citation of such a paper should account for its provisional character. A revised version may be available directly from the author. 


\section{ABSTRACT \\ Smoking, Drinking, Never Thinking of Tomorrow: Income and Risky Choices amongst Young Adults in the UK}

In this paper we look at the relationship between health and income as mediated by "lifestyle" choices; that is, a set of behaviours which are thought to influence health and are generally considered to invoke a substantial degree of free choice. The main underlying assumption is that individuals are co-producers of their own health. We first present a theoretical model in which health affects a consumer's utility through a Health Production Function in which health is the output and consumer goods are the inputs. We then estimate an empirical model of health related choices and outcomes. We find that there are substantial differences between the permanent and transitory income determinants - also in terms of the direction of the effects. Moreover, we find that income effects often differ significantly in size and sometimes sign according to whether the income change was positive or negative. This is attributed to the dependence creating nature of the consumption goods involved (smoking cigarettes and drinking alcohol) and their role as anxiety reducing goods which suggests that the simple theoretical model outlined here - some form of which is usually employed to analyse these issues - is not fully adequate to deal with the type of lifestyle consumption goods considered here. We indicate the lines along which a model needs to be developed in order to take this more fully into account, based on the rational addiction approach originating with Becker.

JEL Classification: D11, D12, I12, J13

Keywords: health, lifestyle, income, young people

Corresponding author:

Niall O'Higgins

Department of Economics and Statistics

University of Salerno

Via Giovanni Paolo II

132-84084 Fisciano (SA)

Italy

E-mail: nohiggins@unisa.it 


\section{Introduction}

In this paper we look at the relationship between health and income as mediated by "lifestyle" choices; that is, a set of behaviours which are thought to influence health and are generally considered to invoke a substantial degree of free choice (Contoyannis and Jones, 2004). The main underlying assumption is that individuals are co-producers of their own health.

The paper is divided into two parts. First, we present a theoretical model of in which health affects a consumer's utility through a Health Production Function in which health is the output and consumer goods are the inputs. Employing this approach, a Lifestyle Return to Scale (LRS) parameter is defined. The first result is that an increase in a consumer's personal income may have a positive or a negative effect on health; in other words, health may be a normal or an inferior good, depending on the Lifestyle parameter.

In the second part of the paper, we estimate an empirical model of health related choices and outcomes. In the literature there are contrasting findings with some cross-section estimates of income and health finding negative income effects, whilst casual observation (e.g. higher mortality rates amongst the poor) suggesting a positive relation. The explanation for this lies in the distinction between permanent and transitory (or evolutionary) income effects. In what follows, we focus on the latter transitory aspects although, for the purposes of comparison, we report also cross-section estimates. Specifically, we employ two waves (at ages 26 and 29) of the British Cohort Study, a multiple wave longitudinal survey of people born in one week during $5^{\text {th }}-11^{\text {th }}$ ) 1970 , in order to estimate a differenced model of the effects of changes in wage income on changes in health related indicators in order identify current income effects along the lines of the analysis of Dustmann \& Windmeijer (2000).

We find that there are substantial differences between the permanent and transitory income determinants, also in terms of the direction of the effects. Moreover, we find that income effects often differ significantly in size and sometimes sign according to whether the income change was positive or negative. This is attributed to the dependence creating nature of the consumption goods involved (smoking cigarettes and drinking alcohol) and their role as anxiety reducing goods which suggests that the simple theoretical model outlined here - some form of which is usually employed to analyse these issues - is not fully adequate to deal with the type of lifestyle consumption goods considered here. We indicate the lines along which a model needs to be developed in order to take this more fully into account, based on the rational addiction approach originating with Becker (1994). 


\section{A Simple Theoretical Model}

As is well known, at the core of utilitarianism, from which the consumer's utility function is derived, is the assumption that motivations determine human action. These motivations are mostly identified with pleasure and consequent "utility" is (usually) exclusively individual, and its cause is not in itself a central issues of interest for economic analysis.

For this reason, utilitarianism must be seen in the framework of consequentialism in which the analysis is end-state oriented instead of following a-priori approach.

In his Ethics, Spinoza says that good "means every kind of pleasure, and all that conduces thereto, and especially that which satisfies our longing, whatsoever that may be, and by evil, every kind of pain especially what frustrates our longing". For this reason "we in no case desire a thing because we deem a thing good but, contrariwise, we deem a thing good because we desire it" (Spinoza, Ethics Part 3, XXXIX).

However, it is precisely the internal mental conflict that underlies at least some consumer choices which may be useful for the analysis of the consumer's behaviour. This mechanism can be found not only in the thought of the ancient Greeks, such as Plato's tripartite theory of the soul, but even, from a different perspective, in neoclassical theory. For example, Jevons states: " It will be readily conceded that pain is the opposite of pleasure; so that to decrease pain is to increase pleasure; to add pain is to decrease pleasure. Thus we may treat pleasure and pain as positive and negative quantities are treated in algebra. The algebraic sum of a series of pleasures and pains will be obtained by adding the pleasures together and the pains together, and then striking the balance by subtracting the smaller amount from the greater. Our object will always be to maximise the resulting sum in the direction of pleasure, which we may fairly call the positive direction. This object we shall accomplish by accepting everything, and undertaking every action of which the resulting pleasure exceeds the pain which is undergone; we must avoid every object or action which leaves a balance in the other direction" (Jevons, 2009).

This implies that it is possible to model consumer choice through the comparison between pleasure and pain. Furthermore if we include health in the utility function a consumer's choice depends on the weighted comparison between the utility of the products and the subjective relative weight that the same products have on consumer's health.

One of the theoretical results that the model predicts, is that health can be an inferior good even if all other products are normal; the nature of health, as normal, neutral or inferior good, depends on the returns to scale of the health's production function. 


\subsection{Static analysis}

Starting from Wagstaff Model (1986) and also from Contoyannis and Jones's hypothesis (2004), Coppola (2012) developed a micro model of consumer's choice in order to better define a measure of lifestyle and then to explain the effects of consumer's choices on his Health status. The first important result of this model, that we generalize, is that an increase of consumer?s personal income may have a positive or a negative effect on his health if the same consumer has a good or a "bad" lifestyle.

The model includes 2 equations: 1) the consumer's utility function; 2) the health production function. Health is in the consumer's utility function. But in contrast to Wagstaff (1986) and also Contoyannis and Jones (2004), we assume that all commodities are both in the Utility function, and in the Health production function.

In Particularly the arguments of the consumer's utility function are both health and the other commodities. Among these ones there are commodities that may have a positive, null, or a negative impact on health, as for example, smoking, alcohol or drugs.

We define the Consumer's utility function as:

$$
U=u(H, \boldsymbol{m})
$$

where $H$ is Health and $\boldsymbol{m}$ is a commodity vector or commodity bundle. $m_{i} \in \boldsymbol{m}$ is the single commodity.

Furthermore, we assume that $\frac{d U}{d H} \geq 0$ and $\frac{d U}{d m_{i}} \gtrless 0$ and also that exists at least one commodity $m_{i} \in \boldsymbol{m}$ of which the marginal utility $\exists m_{i}: \frac{d U}{d m_{i}}>0$

The Health Production function is given by:

$$
H=h(\boldsymbol{m}, \boldsymbol{\Omega})
$$

where $\boldsymbol{\Omega}$ includes the other factors that affect the health, $\frac{d H}{d m_{i}} \gtrless 0$ and $\exists m_{i}: \frac{d H}{d m_{i}}>0$.

Substituting equation (2) into equation (1), gives:

$$
\begin{gathered}
U=u(h(\boldsymbol{m}, \Omega), \boldsymbol{m}) \\
\frac{d U}{d m_{i}}=\frac{d[u(h(\boldsymbol{m}, \Omega), \boldsymbol{m}]}{d h} \frac{d h(\boldsymbol{m}, \Omega)}{d m_{i}}+\frac{d[u(h(\boldsymbol{m}, \Omega), \boldsymbol{m}]}{d m_{i}}
\end{gathered}
$$


The vector $\boldsymbol{m}$ may be partitioned into sub-vectors:

$$
\boldsymbol{m}^{\prime}=\left[\boldsymbol{m}_{u_{+}, h_{+}}^{\prime}, \boldsymbol{m}_{u_{-}, h_{-}}^{\prime}, \boldsymbol{m}_{u_{+}, h_{-}}^{\prime}, \boldsymbol{m}_{u_{-}, h_{+}}^{\prime}\right]
$$

where $\boldsymbol{m}_{\boldsymbol{u}_{+}, \boldsymbol{h}_{+}}^{\prime}$ is a sub-vector of commodities $m_{i}$ that affect positively both the utility $\left(\frac{d U}{d m_{i}}>0\right)$ and the health $\left(\frac{d H}{d m_{i}}>0\right)$, while $\boldsymbol{m}_{\boldsymbol{u}_{+}, \boldsymbol{h}_{-}}^{\prime}$ is a sub-vector of commodities $m_{i}$ that affect positively affects the consumer's utility $\left(\frac{d U}{d m_{i}}>0\right)$ but negatively his health $\left(\frac{d H}{d m_{i}}<0\right)$, and so on.

The Total effect of a change of $m_{i}$ on utility is equal to:

$$
\frac{d U}{d m_{i}}=\frac{d[u(h(\boldsymbol{m}, \Omega), \boldsymbol{m}]}{d h} \frac{d h(\boldsymbol{m}, \Omega)}{d m_{i}}+\frac{d[u(h(\boldsymbol{m}, \Omega), \boldsymbol{m}]}{d m_{i}}>0
$$

The total effect of a change of $m$ on utility is equal to:

$$
\frac{d U}{d m_{i}}=\frac{d[u(h(\boldsymbol{m}, \Omega), \boldsymbol{m}]}{d h} \frac{d h(\boldsymbol{m}, \Omega)}{d m_{i}}+\frac{d[u(h(\boldsymbol{m}, \Omega), \boldsymbol{m}]}{d m_{i}} \geq 0
$$

The consumer decides how much to consume of the single commodity, through a simple optimization problem:

$$
\begin{gathered}
\operatorname{Max}_{m \geq 0}[u(h(\boldsymbol{m}, \Omega), \boldsymbol{m}] \\
\text { s.t. } \boldsymbol{p}^{\prime} \boldsymbol{m}=y
\end{gathered}
$$

where $\boldsymbol{p}^{\prime}$ is the prices vector and y is income. The solution of the Lagrangian equation gives the optima $m_{i}=m(\boldsymbol{p}, y)$ and $H=h(\boldsymbol{p}, y)$

In order to clarify ideas, let's suppose there are only two commodities: $x \in \boldsymbol{m}_{\boldsymbol{u}_{+}, \boldsymbol{h}_{+}}^{\prime}$ and $z \in \boldsymbol{m}_{\boldsymbol{u}_{+}, \boldsymbol{h}_{-}}^{\prime}$ and Cobb Douglas Utility and health Production function so that, Utility is given by:

$$
U=H^{\alpha} x^{\beta} z^{\delta}
$$

$\alpha, \beta, \delta$ are parameters. $\alpha>=0$ may be considered the weight given on his or her own health by the consumer.

The individual consumes a commodity only if the relevant parameter is positive. We suppose that $\beta>0$ and $\delta>0, \frac{d U()}{d x}>0 ; \frac{d U()}{d z}>0$, and also that $\frac{d^{2} U()}{d x}<0 ; \frac{d^{2} U()}{d z}<0$ 
According Wagstaff (1986) and Contoyannis and Jones (2004) consumption may affect consumer's health, and for this reason the consumer is a co-producer of his health.

For sake of simplicity, let's assume that a commodity can only either better or worsen a consumer's health status. In other words, there is no commodity that has a positive impact on health for small quantities and a negative for stronger doses. It assumes also that $\mathrm{x}$ improve health, while $\mathrm{z}$ worst health..

It is possible to write the Health Production Function

$$
H=h(x, z, \Omega)=\Omega x^{\rho} z^{-\gamma}
$$

$(\rho-\gamma)$ is equal to the elasticity of scale and it can be positive, negative or null. Let $\theta=\rho-\gamma$.

For Sassi and Hurst (2008) individual lifestyles are related to those individual behavioral traits that occupy a central position because of their direct influences on individual health. Also Contoyannis and Jones (2004) define a lifestyle "as a set of behaviours which are considered to influence health" If $\theta>0$ an increase in the consumption of the good has a positive effect on health, while for $\theta<0$ this effect is negative. With $\theta=0$ the consumer behaviour has no effect on health. For this reason the parameter $\theta$ may be defined as the lifestyle Return to Scale (hereafter LRS). Substituting $h(x, z, \Omega)=\Omega x^{\rho} z^{-\gamma}$ into $U=H^{\alpha} x^{\beta} z^{\delta}$, one obtains

$$
\begin{gathered}
U=\Omega^{\alpha} x^{\alpha \rho} z^{-\alpha \gamma} x^{\beta} z^{\delta} \\
U=\Omega^{\alpha} x^{\beta+\alpha \rho} z^{\delta-\alpha \gamma}
\end{gathered}
$$

The elasticity with respect to $x$ become $\alpha \rho+\beta$ and the elasticity with respect to $z$ will be $\delta-\alpha \gamma$. The commodity $z$ will be consumed only if $\delta-\alpha \gamma>0$. Hence, the choice of consuming $z$ depends on 3 parameters: 1 ) the elasticity $\delta$ with respect to $z$, that is to say, the weight that the consumer confers to that good $z ; 2) \alpha$, the importance of the health for the consumer, 3) and the measure of the damage of $z$ on health $(\gamma)$. It is useful to note that consumer can decide to use $z$ even if he knows that $z$ is dangerous for its health. Following this approach, It does not depend only on the level of education. Even the consumer well aware of the damage that smoking produces may continue to smoke if he likes it very much.

Including health in the consumer's utility function increases the consumption of those goods that benefit health and decreases that good which causes damage.

Let $\Omega=1$. $p_{x} x+p_{z} z=Y$ is the consumer's budget constraint where $p_{x}, p_{z}$ are the prices of the 
commodities. $Y$ is income. The consumer maximizes his utility when ${ }^{1}$

$$
\begin{aligned}
\operatorname{Max}_{x, z \geq 0} & {\left[\alpha x^{\beta+\alpha \rho} z^{\delta-\alpha \gamma}\right] } \\
& \text { s.t. } p_{x} x+p_{z} z=y
\end{aligned}
$$

We solve the Lagrangianian $\operatorname{Max}_{x, z} L=U(x, z)-\lambda\left(p_{x} x+p_{z} z-Y\right)$. where $\lambda$ is the Langrage Multiplier. At the optimum the goods consumed are:

$$
\begin{aligned}
& x=\frac{\beta+\alpha \rho}{\beta+\delta+\alpha(\rho-\gamma)} \frac{y}{p_{x}} \\
& z=\frac{\delta-\alpha \gamma}{\beta+\delta+\alpha(\rho-\gamma)} \frac{y}{p_{z}}
\end{aligned}
$$

The weight of health $\alpha$, increases the consumption of "virtuous" commodity and reduce the consumption of harmful commodity. At the optimum, the health level is

$$
\begin{gathered}
H=\left(\frac{\beta+\alpha \rho}{\beta+\delta+\alpha(\rho-\gamma)} \frac{Y}{p_{x}}\right)^{\rho}\left(\frac{\delta-\alpha \gamma}{\beta+\delta+\alpha(\rho-\gamma)} \frac{Y}{p_{z}}\right)^{-\gamma} \\
H=\left(\frac{\beta+\alpha \rho}{\beta+\delta+\alpha(\rho-\gamma)}\right)^{\rho}\left(\frac{\delta-\alpha \gamma}{\beta+\delta+\alpha(\rho-\gamma)}\right)^{-\gamma} \frac{\left(p_{z}\right)^{\gamma}}{\left(p_{x}\right)^{\rho}} y^{(\rho-\gamma)}
\end{gathered}
$$

Where $\left(\frac{\beta+\alpha \rho}{\beta+\delta+\alpha(\rho-\gamma)}\right)$ and $\left(\frac{\delta-\alpha \gamma}{\beta+\delta+\alpha(\rho-\gamma)}\right)$ are respectively the share of commodities $x$ and $z$ weighted for their own elasticity with respect to health. The level of health and the price of virtuous good are negatively correlated. If the price of good $x$ increases (decreases), it worsens (betters) the level of health while if it decrease then it improves health conditions. On the contrary $H$ improves (worsens) if the price of $z$ increases (decreases). The elasticity of health with respect to income is $\rho-\gamma=\theta$, the parameter LRS. Unlike the other parameters that can have only one sign, the elasticity of health with respect to income may be positive or negative. If $\rho-\gamma=0$ income growth does not affect the level of health. If $\rho-\gamma<0$, income affects health negatively. If $\rho-\gamma>0$ it affects it positively. In other words, health may be an inferior "good" $(\gamma>\rho)$, even if all the other

\footnotetext{
${ }^{1}$ This approach may be considered as a generalization of Wagstaff's model (1986). The Wagstaff Model is a special case of this Consumer's model where $\beta=0(\operatorname{good} x$ is not in the Consumer's utility function) and with $\gamma=0$ ( $z$ doesn't affect health). The main differences are: 1) in the Wagstaff model health can only be a normal good because $\frac{d h(x)}{d Y}>0$. On the contrary in the model proposed in this paper 1) health may be also an inferior good; and 2) the level of health depends on the lifestyle of the consumer.
} 
commodities used by the consumer are normal "goods".

\subsection{Dynamic analysis}

The model still doesn't explain, however, both in its general form or in its simplified Cobb Douglas incarnation, the existence of possible asymmetric effects. These may be explained by introducing the notion of generalized addiction.

In fact, if we suppose that the commodities that are bad one?s health, such as cigarettes and alcohol, are also those ones that are addictive, we need to to relax the additive-separability assumption in order to model the consumption of addictive goods (Becker et al. 1994).

Furthermore we can consider a simple model of Grossman and Chaloupka (1998) that, following Becker et al. (1994), assume that consumers maximize a lifetime utility function given by:

$$
V=\sum_{t=1}^{\infty} \mu^{t-1} U\left(C_{1, t}, C_{2, t}, C_{2, t-1}, e_{t}\right)
$$

Where $C_{1, t}$ is consumption of non-additive good at time $t$ and $C_{2, t}$ is consumption of an additive good at age $t-1$, e reflects the effects of measured and unmeasured life cycle variables on utility and $\mu$ is the time discount factor. In our case, we can assume that $C_{1}$ is the commodity named $x$ and $C_{2}$ is $z$.

If the utility function is quadratic and the rate of time preferences is equal to the market rate of interest, the motion equation of the current consumption of addictive good is

$$
z_{t}=\xi z_{t-1}+\mu z_{t+1}+\xi_{1} P_{t}+\xi_{2} e_{t}
$$

$\xi, \xi_{1}, \xi_{2}$, are nonzero parameters. Substituting $z_{t-1}$ in $z_{t}$ and so on, it becomes:

$$
z_{t}=\frac{1}{1-\mu \xi^{2}}\left[x i_{1} \sum_{i=0}^{T} \xi^{i} P_{t-i}+\xi_{2} \sum_{i=0}^{T} \xi^{i} e_{t-1}+\mu \sum_{i=1}^{T} \xi^{2+i} z_{t-i}+\mu \xi z_{t+1}+\xi^{i} z_{t-i}\right]
$$

This means that the consumption at time $t$ depends essentially on the moving average of the errors (shocks). If we decompose the error term $e_{t}$ into

$$
e_{t}=\omega_{1} e_{+, t}+\omega_{2} e_{-, t}
$$


and suppose that the positive errors and the negative errors have a different impact on consumption we obtain the asymmetric effects

$$
z_{t}=\frac{1}{1-\mu \xi^{2}}\left[\xi_{1} \sum_{i=0}^{T} \xi^{i} P_{t-i}+\xi_{3} \sum_{i=0}^{T} \xi^{i} e_{-, t-1}+\xi_{3} \sum_{i=0}^{T} \xi^{i} e_{+, t-1}+\mu \sum_{i=1}^{T} \xi^{2+i} z_{t-i}+\mu \xi z_{t+1}+\xi^{i} z_{t-i}\right]
$$

Furthermore, with $\xi_{3}>0$ and $x i_{4}<0$ any shock, both positive and negative, will cause an increase of the consumption of $z$, and with $\xi_{3}=-\xi_{4}$ the consumption of $z$ depends on the absolute errors. In other terms, any shock, both positive or negative, causes an increase of $z_{t}$.

\section{Empirical analysis}

The model outlined provides the theoretical justification for either positive or negative income effects with regard to the consumption of goods which provide both direct utility benefits and indirect disutility through their health effects which in turn will depend on individuals' preferences. The model leads fairly naturally to empirical estimation of behavioural choices likely to affect health. In this section, we look at two specific types of 'consumption' behaviour likely to be detrimental to health - smoking tobacco products and drinking alcohol - as well as at one 'intermediate' outcome of health related behaviour - the body mass index, and a (subjective) measure of the 'final' outcome, the state of health of the individual -. Using longitudinal data we estimate the effects of changes in wage income on changes in the afore-mentioned health related indicators so as to identify the effects of current/transitory income changes on health related behaviour and outcomes. In this we distinguishing from permanent income (and other non-income related time invariant effects) which show up in the cross-section results. For comparison purposes, we also the latter in the main tables. The focus on a dynamic model also attenuates the potential endogeneity of income effects. That is, rather obviously, a negative correlation between unhealthy behaviour and wages may arise as a consequence of unhealthy workers earning less. Equally obviously, regressing temporal changes on temporal changes, any time invariant characteristic influencing the dependent variable disappears. The most closely related precursor of this analysis is the paper by Dustmann \& Windmeijer (2000) which identifies transitory income effects on behaviour through a differencing approach similar to that adopted here.

This analysis presented here is also related to a line of research concerned with dependency in consumption $^{2}$; Cigarettes and alcohol, as well as having negative health effects are also goods

\footnotetext{
${ }^{2}$ See, for example the substantial body of research initiated by Becker et al. (1994) on rational addiction.
} 
which create dependence in consumers ${ }^{3}$; this implies that consumption of the good now is likely to be highly correlated with consumption of the good yesterday. Similarly, an excessively high BMI may also be the consequence of compulsive behaviour. A related albeit slightly more subtle issue which we consider here lies also in the potential for these goods (that is, cigarettes, alcohol and food) to reduce anxiety in some individuals. All three of these types of good are commonly associated, for some at least, with the (short-term) reduction of anxiety. If we consider any movement from the existing status quo as a shock - not just in the purely economic sense of an exogenous change in a variable which determines some type of behaviour - but in its more literal sense of a disturbing event, this raises the possibility that the effects of wage changes may have more than one component - an effect simply due to the size and direction of the variation (as formulated in the theoretical model above) and an effect due to the event of change in itself. Simply stated, preferences may, in some sense be reference dependent. This in turn implies the possibility art least that the effects of wage changes may be asymmetric around their current level. There is no reason to suppose a priori that positive and negative wage changes will equal but opposite effects on consumption behavior. We will return to this in our discussion of the results. Consequently, we estimate equations of the form:

$$
z_{i t}-z_{i t-1}=f\left(\alpha+\beta D_{\text {pos }}\left(\left(\operatorname{Ln}\left(y_{i t}\right)-\operatorname{Ln}\left(y_{i t-1}\right)\right)+\gamma D_{n e g}\left(\operatorname{Ln}\left(y_{i t}\right)-\operatorname{Ln}\left(y_{i t-1}\right)\right)\right)\right.
$$

Where $z$ is the health related indicator of interest and $y$ is wage income; $D_{\text {pos }}$ is a dummy taking a value of 1 if the change in income is positive and is 0 otherwise whilst $D_{n e g}$ conversely takes a value of 1 if the change in income is negative and is 0 otherwise. The dummy thus allows us to distinguish between the effects of positive and negative income changes which, given the potentially dependence creating nature of the types of behavior under study, and more generally, the notion that some form of reference-dependence may drive differential reactions to positive and negative income changes, we believe is likely to be important.

Using a differenced equation simplifies the analysis in that all the time invariant variables drop out (thus, for example, excluding the need for individual fixed effects) and we can reasonably assume that the price differences over time are roughly constant across individuals, or at least of minor importance in determining the results. Using the log difference in wage as an explanatory variable implies that, since $\operatorname{Ln}\left(y_{i} t\right)-\operatorname{Ln}\left(y_{(} i t-1\right)$ percentage change in wage, the coefficient $\beta$ measures the effect of wage changes in percentage terms.

\footnotetext{
${ }^{3}$ We do not wish to enter into here any discussion of the nature of dependence and, in particular, whether some individuals are more prone to becoming dependent on specific substances or behaviours and so on.
} 


\subsection{Data}

The empirical analysis employs data from of two waves of the British Cohort Study (BCS); a multiple wave longitudinal survey-based study of people born in one week during April $\left(5^{\text {th }}-11^{\text {th }}\right)$ 1970. The BCS has collected a wide range of information on participants throughout their lives to date. We use data from the two waves undertaken at age 26 and 29.

We consider the effects of the change in wage income for all those who were in dependent employment at both age 26 and 29. The idea being to examine the effects of wage changes but to exclude from the analysis potentially traumatic events per se such as the complete loss of employment and its attendant effects on behaviour (and health) independent of the income effect in itself.

The dependent variables employed are concerned with two types of behaviour likely to negatively affect individual?s health, as well as one intermediate and one 'final' health related outcome variable. Specifically, we consider the effects of wages changes on:

\section{- Lifestyle}

Given the nature of these behaviours we look at transitions out of and into the state of habitually indulging in them specifically we look at:

- Smoking - The base variable uses a $1 / 0$ dichotomy according to whether the person is a regular smoker at time $x$ or not; consequently, in the dynamic (differenced form) this takes we estimate two probit models which estimate:

* The probability of starting to smoke between ages 26 and 29, given that the person is a non-smoker at age 26 ; and,

* The probability of stopping smoking between ages 26 and 29, given that the person is a smoker at age 26 ;

- Drinking - here, the base variable uses a 1/0 dichotomy according to whether the person is the person a regular drinker (that is, whether the person drinks every day nearly every day) - again, the dynamic form involves the estimation of two forms which examine transitions from one state to another. Specifically:

* The probability of becoming a regular drinker between ages 26 and 29, given that the person is not a regular drinker at age 26 ; and,

* The probability of stopping smoking between ages 26 and 29, given that the person is a smoker at age 26

\section{- Health relate outcomes}




\section{- Intermediate health indicator $=$ Body Mass Index (BMI).}

Here OLS is applied to (changes in) the Body Mass Index between age 26 and 29

- Self reported state of health - based on a four point scale running from 'Excellent' $(=1)$ to 'Poor' $(=4)$, an ordered probit model is estimated here, in the dynamic (differenced) form, this is applied to the change in the self-reported state.

In each case a single explanatory variable, the (change in the) natural log of Hourly Wage Rate of full-time employees is employed. In a second stage, we also report the effects of wages on behavior and health outcomes separately for young men and young women.

\subsection{Results}

Table 1 reports the results for smoking. The main results of interest are reported in the first two numerical columns which report the results of the dynamic model, whilst the third and fourth report the corresponding cross-section estimates. Note that the first column reports the value of $\beta$; the effect of the percentage wage change, given that it was positive. The second reports the value of $\gamma$; specifically, the difference between a negative and a positive wage change in terms of its 'impact' on the dependent variable. Although the effects are often not statistically significant in the differenced equation, the results suggest a consistently negative relation between smoking and income changes; wage changes are positively correlated with stopping smoking and negatively (and statistically significantly) correlated with starting smoking. In both cases, the effects of negative changes are stronger than positive ones, although the difference is not statistically significant in either case. One can also observe that the only statistically significant parameter in the dynamic model is the negative relation between increases in wages and starting smoking. Ceteris paribus, positive shifts in income are likely to discourage young people from starting smoking. It may also be noted in passing that columns 3 and 4 show the strong and statistically significant negative relation between wages and income at both ages 26 and 29. Hence in this case, all the effects, short-run and long-run as well as both positive and negative wage change effects are consistent.

However, if we look at the results of estimating the models separately by gender, an interesting difference emerges between young men and young women; one can observe that the null effect of wages on giving up smoking is the sum of two opposing and statistically significant effects for males and females. Whilst for young men a wage rise makes it more likely that a young man will stop smoking (or less likely that he will start if didn't smoke at age 26), for young women a wage rise is actually associated with a reduced probability of giving up smoking. One might also observe that for a negative change in wages, the opposite albeit not statistically significant effect of wages is observed - a fall in wages makes is associated with a lower probability that a young woman will give 
Table 1: Effects of wage changes on smoking. Probit Model

\begin{tabular}{|c|c|c|c|c|c|}
\hline & & \multicolumn{2}{|c|}{$\begin{array}{c}\text { Change in status } \\
(1996-1999)\end{array}$} & \multirow{2}{*}{$\begin{array}{c}\text { Cross Section } \\
(1996) \\
\text { Log(Wage })\end{array}$} & \multirow{2}{*}{$\begin{array}{c}\text { Cross Section } \\
(1999) \\
\text { Log(Wage })\end{array}$} \\
\hline & & $\begin{array}{r}\% \Delta \text { Wage } \\
\text { positive }\end{array}$ & $\begin{array}{c}\% \Delta \text { Wage } \\
\text { negative }\end{array}$ & & \\
\hline \multirow[t]{3}{*}{ Stop (if smoker at 26) } & Coeff. & .03 & .54 & & \\
\hline & Std. err. & .16 & .48 & & \\
\hline & $\mathrm{n}$ & \multicolumn{2}{|c|}{951} & & \\
\hline \multirow{3}{*}{ Start (if non-smoker at 26) } & Coeff. & $-.28^{* *}$ & -.37 & & \\
\hline & Std. err. & .14 & .25 & & \\
\hline & $\mathrm{n}$ & \multicolumn{2}{|c|}{3172} & & \\
\hline \multirow{3}{*}{ Smoker (at 26 or 29 ) } & Coeff. & & & $-.46^{* * *}$ & $-.28^{* * *}$ \\
\hline & Std. err. & & & $(.06)$ & $(.04)$ \\
\hline & $\mathrm{n}$ & & & 4258 & 4612 \\
\hline
\end{tabular}

up smoking. One might observe that although not significantly different from zero, the difference between the coefficients on positive and negative wage changes is statistically significant $(\mathrm{p}<.05)$ for young women; The implication is that positive and negative wage changes have different opposing - effects on young women's decisions to give up smoking.

The opposing sign for wage effects emerges even more strongly as regards drinking behaviour (table 3). Looking first at the estimates of becoming a 'regular' (some might say heavy) drinker, both increase and decreases in the current wage lead to an increase in the probability of becoming a habitual drinker (given that the person was not one at age 26). Both of the effects are statistically significant (at at least 10\%) and, as would be expected given the opposing directions of the effects, so is the difference between the effects of positive and negative wage changes; it would appear that young people drink to celebrate their wage gains, but even more so to drown the sorrows associated with wage losses. Although weaker in terms of statistical significance, the effects are closely mirrored in the coefficient estimates concerned with stopping drinking; both wage gains and losses tend to reduce the likelihood of going on the wagon. This contrasts with the long-term relation which is unequivocally positive. Clearly these results are not explainable in terms of the simple static neoclassical utility function outlined initially and some modification to take into account some form of reference dependence, or indeed some other explanation, is needed.

Once again there are clear differences across gender. In this case, the apparently inconsistent (as 
Table 2: Effects of wage changes on smoking. Probit Model by Gender

\begin{tabular}{|c|c|c|c|c|c|}
\hline & & \multicolumn{4}{|c|}{ Change in status $1996-1999$} \\
\hline & & \multicolumn{2}{|c|}{ Male } & \multicolumn{2}{|c|}{ Female } \\
\hline & & $\begin{array}{l}\% \Delta \text { Wage } \\
\text { positive }\end{array}$ & $\begin{array}{c}\% \Delta \text { Wage } \\
\text { negative }\end{array}$ & $\begin{array}{c}\% \Delta \text { wage } \\
\text { positive }\end{array}$ & $\begin{array}{c}\% \Delta \text { wage } \\
\text { negative }\end{array}$ \\
\hline \multirow[t]{3}{*}{ Stop (if smoker at 26) } & Coeff. & $.48^{* *}$ & .34 & $-.48^{* *}$ & .73 \\
\hline & Std. err. & .22 & .56 & .24 & .59 \\
\hline & $\mathrm{n}$ & \multicolumn{2}{|c|}{.524} & \multicolumn{2}{|c|}{427} \\
\hline \multirow[t]{3}{*}{ Start (if non-smoker at 26) } & Coeff. & $-.53^{* * *}$ & $-.45^{*}$ & .03 & -.33 \\
\hline & Std. err. & .20 & .24 & .21 & .25 \\
\hline & $\mathrm{n}$ & \multicolumn{2}{|c|}{1617} & \multicolumn{2}{|c|}{1555} \\
\hline
\end{tabular}

Table 3: Effects of wage changes on drinking. Probit Model

\begin{tabular}{|c|c|c|c|c|c|}
\hline \multirow[t]{2}{*}{ Drinking } & & \multicolumn{2}{|c|}{$\begin{array}{c}\text { Change in status } \\
(1996-1999)\end{array}$} & \multirow{2}{*}{$\begin{array}{c}\text { Cross Section } \\
(1996) \\
\text { Log(Wage })\end{array}$} & \multirow{2}{*}{$\begin{array}{c}\text { Cross Section } \\
(1999) \\
\text { Log(Wage })\end{array}$} \\
\hline & & $\begin{array}{c}\% \Delta \text { Wage } \\
\text { positive }\end{array}$ & $\begin{array}{c}\% \Delta \text { Wage } \\
\text { negative }\end{array}$ & & \\
\hline \multirow[t]{3}{*}{ Stop being regular drinker (if one at 26 ) } & Coeff. & $-.33^{*}$ & .13 & & \\
\hline & Std. err. & $(.20)$ & $(.45)$ & & \\
\hline & $\mathrm{n}$ & \multicolumn{2}{|c|}{450} & & \\
\hline \multirow[t]{3}{*}{ Become a regular drinker (if not one at 26 ) } & Coeff. & $.28^{* * *}$ & $-.38^{*}$ & & \\
\hline & Std. err. & $(.10)$ & $(.21)$ & & \\
\hline & $\mathrm{n}$ & \multicolumn{2}{|c|}{3673} & & \\
\hline \multirow{3}{*}{ Regular drinker (at 26 or 29 ) } & Coeff. & & & $.17^{* *}$ & $.24^{* * *}$ \\
\hline & Std. err. & & & $(.07)$ & $(.04)$ \\
\hline & $\mathrm{n}$ & & & 4215 & 4615 \\
\hline
\end{tabular}


far as the simple neo-classical model is concerned) results are driven by the behaviour of young men (table 4). For young men, both increased wages and decreased wages are associated with a greater likelihood of becoming a regular (heavy) drinker. It might be observed that, again for young men, also stopping drinking has the same apparent contradiction; in this case however, the estimated parameters are not statistically significant, although the difference between them is. For young women, alcohol consumption demonstrates the more conventional demand characteristics of a normal good, with increases in wages being associated with drinking more and wages cuts associated with drinking less.

Table 4: Effects of wage changes on drinking. Probit Model by Gender

\begin{tabular}{|c|c|c|c|c|c|}
\hline & & \multicolumn{4}{|c|}{ Change in status 1996 - 1999} \\
\hline & & \multicolumn{2}{|c|}{ Male } & \multicolumn{2}{|c|}{ Female } \\
\hline & & $\begin{array}{r}\% \Delta \text { Wage } \\
\text { positive }\end{array}$ & $\begin{array}{c}\% \Delta \text { Wage } \\
\text { negative }\end{array}$ & $\begin{array}{c}\% \Delta \text { Wage } \\
\text { positive }\end{array}$ & $\begin{array}{c}\% \Delta \text { Wage } \\
\text { negative }\end{array}$ \\
\hline Stop being regular drinker (if one at 26 ) & Coeff. & -.42 & .76 & -.26 & -.08 \\
\hline & Std. err. & .27 & .80 & .31 & .41 \\
\hline & $\mathrm{n}$ & \multicolumn{2}{|c|}{290} & \multicolumn{2}{|c|}{160} \\
\hline \multirow[t]{3}{*}{ Become a regular drinker (if not one at 26 ) } & Coeff. & $.32^{* *}$ & $-.65^{* * *}$ & .17 & -.09 \\
\hline & Std. err. & .12 & .21 & .16 & .30 \\
\hline & $\mathrm{n}$ & \multicolumn{2}{|c|}{1851} & \multicolumn{2}{|c|}{1822} \\
\hline
\end{tabular}

Looking now more explicitly at health related outcomes, table 5 reports the results of an OLS regression of the change in BMI on wages. Whilst the cross-section results are clear and unequivocal - wages are negatively correlated with income - the relation between wage changes and changes in BMI are weak and not statistically significant, although here too the sign of the wage effects changes according to whether the change is positive or negative. The results by gender (not reported here) also display moderately different characteristics by gender BMI being positively associated with wages for young men and negatively for young women, however, none of these results are statistically significant and they are not reported here.

As regards the main outcome variable, self-reported health, the results are similar to, albeit clearer than those for BMI (table 6). Note first that the scale used ranges from 1 (excellent health) to 4 (poor health) so that an increase in the scale reflects a worsening of an individual's health. Consequently, on the reasonable assumption that higher BMI (generally) implies a worsening of 
Table 5: Effects of wage changes on BMI. OLS estimation

\begin{tabular}{|c|c|c|c|c|c|}
\hline BMI & \multicolumn{2}{|c|}{$\begin{array}{c}\text { Change in status } \\
\mathbf{( 1 9 9 6 - 1 9 9 9 )}\end{array}$} & $\begin{array}{c}\text { Cross Section } \\
(1996)\end{array}$ & $\begin{array}{c}\text { Cross Section } \\
(1999)\end{array}$ \\
\hline & $\begin{array}{c}\% \Delta \text { Wage } \\
\text { positive }\end{array}$ & $\begin{array}{c}\% \Delta \text { Wage } \\
\text { negative }\end{array}$ & Log(Wage) & Log(Wage) \\
\hline BMI & Coeff. & -.02 & -.09 & $-.48^{* * *}$ & $-.25^{* *}$ \\
\hline & Std. err. & $(.16)$ & $(.29)$ & $(.17)$ & $(.12)$ \\
\hline & $\mathrm{n}$ & \multicolumn{2}{|c|}{3201} & 3421 & 4456 \\
\hline
\end{tabular}

health ${ }^{4}$, the results in the table are immediately comparable to those for BMI - at least in terms of the direction of the effects. As before, in the cross-section estimates, wages are clearly positively related to (good) health. However, in the dynamic model, wage changes are only influential if they are negative when young men and young women are taken together; lower wages are associated with worse health. Increased wages appear to produce no beneficial effects on health, but wage falls lead to a worsening. Here too there is clear evidence of reference dependence worthy of further investigation.

Table 6: Effects of wage changes on self-reported health. Ordered Probit Model

\begin{tabular}{|c|c|c|c|c|c|}
\hline Health & & \multicolumn{2}{c|}{$\begin{array}{c}\text { Change in status } \\
\mathbf{( 1 9 9 6 - 1 9 9 9 )}\end{array}$} & $\begin{array}{c}\text { Cross Section } \\
(1996)\end{array}$ & $\begin{array}{c}\text { Cross Section } \\
(1999)\end{array}$ \\
\hline & & $\begin{array}{c}\% \Delta \text { Wage } \\
\text { positive }\end{array}$ & $\begin{array}{c}\% \Delta \text { Wage } \\
\text { negative }\end{array}$ & Log(Wage) & Log(Wage) \\
\hline Self Reported Health & Coeff. & .01 & $-.27^{* *}$ & $-36^{* * *}$ & $-16^{* * *}$ \\
\hline & Std. err. & $(.08)$ & $(.14)$ & $(.05)$ & $(.03)$ \\
\hline & $\mathrm{n}$ & \multicolumn{2}{|c|}{4107} & 4241 & 4614 \\
\hline $\begin{array}{l}\text { Note: Statistical significance is indicated thus: } \\
* * * \text { indicates } p<.01 ; * * \text { indicates } p<.05 ; * \text { indicates } p<.10 .\end{array}$ \\
\hline
\end{tabular}

Separating the sexes, one finds that for both young men and young women negative income changes are associated with worsening health, although this is only statistically significant for young men.

\footnotetext{
${ }^{4}$ Although possibly a more appropriate model might consider both extremes of the BMI distribution, although the small numbers at the lower end of the distribution suggest that this would not make a great deal of difference to the results.
} 
Table 7: Effects of wage changes on self-reported health by gender. Ordered Probit Model

\begin{tabular}{|c|c|c|c|c|c|}
\hline & & \multicolumn{4}{|c|}{ Change in status 1996 - 1999} \\
\hline & & \multicolumn{2}{|c|}{ Males } & \multicolumn{2}{|c|}{ Females } \\
\hline & & $\begin{array}{l}\% \Delta \text { Wage } \\
\text { positive }\end{array}$ & $\begin{array}{c}\% \Delta \text { Wage } \\
\text { negative }\end{array}$ & $\begin{array}{l}\% \Delta \text { Wage } \\
\text { positive }\end{array}$ & $\begin{array}{c}\% \Delta \text { Wage } \\
\text { negative }\end{array}$ \\
\hline Self Reported Health & Coeff. & -.05 & $-.34^{* *}$ & .05 & -.23 \\
\hline & Std. err. & .08 & .16 & .09 & .15 \\
\hline & $\mathrm{n}$ & \multicolumn{2}{|c|}{2174} & \multicolumn{2}{|c|}{2229} \\
\hline
\end{tabular}

\section{Conclusion}

In this paper we have proposed a simple model of health repeated behavior and subjected it to empirical testing using a detailed longitudinal database. The purpose is fairly limited, however, there are several findings of interest. First, there are major differences between the results of crosssection estimation and the differenced approach - as might have been expected. Throughout, the cross-section results suggest that health related behaviour and, as a consequence, health itself are normal goods; wages are positively associated with behavior likely to improve health - reducing drinking, stopping smoking and health itself measured in terms of (a lower) BMI and/or selfreported health status. The differenced model present here with its focus on transitory changes, however, makes it clear that the relationship between wages and health related choices is not so straightforward. Indeed, the differenced model which may more reasonably be considered as a causal relation between short-term wage changes and variations in health status or related behavior, suggests that the simple neoclassical utility function considered in the first part of the paper is not always adequate to capture the nature of these effects. Specifically, in the case of smoking and even more so in the case of drinking behaviour, the choices made are often not consistent with the simple static theoretical model presented at the outset.

A consideration of the effects separately by gender allows these apparently contradictory effects to emerge more clearly. Above-all, there is very clear evidence that for alcohol consumption amongst young men, any reason is a good one to go out and get drunk. The probability of a young man becoming a regular (heavy) drinker increases if his wage rises and increases also if his income falls. How can such behavior be explained? At least two fairly obvious possibilities present themselves. First, it may be that there is some form of reference dependence at the status quo; simply stated there is a kink in the 'value' function at zero (corresponding to the status quo). A second possibility is that wage changes have more than one effect - an effect due to the magnitude and sign of the change in wages as in the standard utility maximizing framework outlined above; and, second effect which arises due to the fact of change in itself - in this view, wage change may be viewed as a shock 
- not in the typical economic sense of an exogenous change in a variable influencing the values of other variables - but rather in its more normal meaning in the English language of a traumatic event. In this view, the change itself causes a trauma to the individual which can be 'treated' by recourse to greater consumption of alcohol or cigarettes. The second interpretation - itself a form of reference dependence, although not quite in the sense intended by Kahneman and Tversky $(1979,1991)$, is given strength by the fact that cigarettes and alcohol are often considered, at least by regular users, to be goods which tend to reduce anxiety, "I need a drink after that," and so on. To formalize such a proposition goes beyond the scope of this chapter, however, its existence suggests interesting areas for further research. One possibility would be to go back to Epicureus, considered one of the forerunners of modern utility theory, and his notion of 'static pleasure'. In any event such speculation goes beyond our more limited purpose here, however, we believe that the peculiar relation between wages changes and behaviour identified here would clearly bear further study.

\section{$5 \quad$ References}

Becker G.S. Grossman M. Kevin M. (1994) An Empirical Analysis of Cigarette Addiction The American Economic Review, Vol 84, No 3, pp 396-418

Becker G.S. Murphy K.M. (1988) A Theory of Rational Addiction The Journal of Political Economy, Vol. 96, No 4, pp. 675-700

Berger M.C. Leigh J.P. (1989) Schooling, Self-Selection, and Health The Journal of Human Resource, Vol. 24, No 3. (Summer,1989), pp. 433-455

Blondel S. Lohéac Y. Rinaudo S. (2007) Rationality and drug use: An experimental approach, Journal of Health Economics, 26, 643-658

Borg V. Kristensen T. (2000) Social class and self-rated health: can the gradient be explained by differences in life style or work environment? Social Science and Medicine 51, 1019-1030.

Contoyannis P. Jones A.M. (2004) Socio-economic Status, Health and Lifestyle, Journal of Health Economics, 23, 965-995

Destefanis S. Sena V. (2006) Health Capabilities and Functionings: An Empirical Analysis for the U.K CSEF Working Paper n.151

Dustmann C. Windmeijer F. (1999) Wages and the Demand for Health: A Life Cycle Analysis The Institute for Fiscal Studies Working Paper Series No. W99/20 
Fuchs V. (1982) Time Preference and Health: An Exploratory Study In: Fuchs, V. (Ed.), Economic Aspects of Health. University of Chicago Press, pp. 93-120.

Fuchs V. (1986) The Health Economy first ed. Harvard University Press, Cambridge, MA.

Grossman M. (1972) On the Concept of Health Capital and the Demand for Health, Journal of Political Economy, Vol. 80, No 2., pp. 223-255

Hu T.-W. Ren Q.-F. Keeler T. Bartlett J. (1995) The demand for cigarettes in California and behavioural risk factors. Health Economics 4, 7-14.

Jevons WS (1888) The Theory of Political Economy Third Edition MacMillian and Co.London

Kahneman D. Tversky A. (1979) Prospect Theory: An Analysis of Decision under Risk Econometrica, Vol. 47, No. 2.: 263-292.

Kahneman D. Tversky A. (1991) Loss Aversion in Riskless Choice: A Reference-Dependent Model The Quartely Journal of Economics

Kenkel D. (1991) Health behaviour, health knowledge and schooling. Journal of Political Economy 99, 287-305.

Kenkel D. (1995) Should you eat breakfast? Estimates from health production functions. Health Economics 4,15-29.

Kip Viscussi W. Evans WN. (1990) Utility Function that Depend on Health Status, American Economic Review, Vol. 80 No.3., pp. 353-374

Mas-Colell A. Whinston M. Green J. (1995) Microeconomic Theory, Oxford University Press,

Sassi F. and Hurst J. (2008) The Prevention of Lifestyle related Chronic Diseases: An Economic Frameword OECD Health Working Paper n.32

Spinoza B. (2007) The Etichs Translated by R.H.M. Elwes Wilder Publications

Strauss J. (1986) Does Better Nutrition Raise Farm Productivity? Journal of Political Economy 94

Varian H. (1992) Microeconomic Analysis, III ed., Norton

Wagstaff A. (1986) The Demand for Health: A Simplified Grossman Model Bulletin of Economic Research 38:1, 1986, 93-95 